\title{
A TUTELA PENAL NO CONTROLE DO TRÁFEGO DE MOEDA: A ATIPICIDADE PENAL DAS OPERAÇÕES DÓLAR-CABO
}

THE CRIMINAL GUARANTEE IN THE CONTROL OF CURRENCY TRAFFIC: THE CRIMINAL ATTIPICITY OF DOLLAR-CAPE OPERATIONS

Camila Mauss BECKER ${ }^{1}$

ISSUE DOI: $10.21207 / 1983.4225 .498$

\section{RESUMO}

Lançando mão da análise da espécie delitiva constante no caput do artigo 22 da Lei $\mathrm{n}^{\circ}$ 7.492/1986 (crime de evasão de divisas) e do sistema de compensação de valores, dólar-cabo, o presente trabalho irá analisar a (a)tipicidade existente na atividade dólar-cabo em face ao delito de evasão de divisas.

Palavras Chave: Evasão de divisas. Dólar-cabo. Lei nº 74.92/86. Tipicidade.

\footnotetext{
${ }^{1}$ Mestranda em Ciências Criminais pelo Programa de Pós-Graduação em Ciências Criminais (PPGCCRIM) da Pontifícia Universidade Católica do Rio Grande do Sul (PUCRS). Especialista em Ciências Penais pela Pontifícia Universidade Católica do Rio Grande do Sul (PUCRS). Advogada criminalista no escritório Fayet Advogados Associados, desde 2013. Endereço: Rua Irmão José Otão, n ${ }^{\circ} 540$, apto. 1305, bairro Independência, Porto Alegre/RS. Fone: (51) 9-8211-6023. E-mail: camila@ fayet.adv.br
} 


\section{CONSIDERAÇÕES INICIAIS DO DELITO DE EVASÃO DE DIVISAS.}

O delito de evasão de divisas, disposto no artigo 22 da Lei $\mathrm{n}^{\circ}$ 7.492/86, foi introduzido no Direito Penal brasileiro a fim de possibilitar a punição de condutas que resultassem na saída irregular de divisas do País ou daquelas que deixassem de declarar os depósitos mantidos no exterior. ${ }^{2}$ Para isso, o artigo 22 da Lei $n^{\circ} 7.492 / 86$ dispõe três hipóteses típicas: a primeira de realização de operação de câmbio não autorizada, com o fim de promover evasão de divisas do País (caput), a segunda de evasão de moeda ou de remessa de divisa para o exterior sem autorização legal (parágrafo único, $1^{\mathrm{a}}$ parte), e, a terceira, de manutenção de depósitos no exterior não declarados à autoridade competente (parágrafo único, $2^{\mathrm{a}}$ parte).

Assim, o legislador, nas três formas delitivas contidas no artigo 22 da Lei $\mathrm{n}^{\circ} 7.492 / 86$, teve um objetivo principal: o de garantir e manter a estabilidade do Sistema Financeiro Nacional evitando que instituições financeiras ou entes assemelhados ajam de forma irregular, efetuando saídas clandestinas de moeda ou mantendo-as no estrangeiro à míngua de qualquer controle Estatal. ${ }^{3}$

Destarte, é possível estabelecer que a tutela da norma penal disposta no artigo 22 da Lei $\mathrm{n}^{\mathrm{o}} 7.492$ possui duplo objetivo: em primeiro, no caput do artigo, o de proteger as reservas cambiais do País ${ }^{4}$, controlando as operações de compra e venda de moeda estrangeira, no intuito de manter a economia do País em constante equilíbrio, e, em segundo, no parágrafo único, a tutela penal recai sobre o Fisco, na medida em que "a saída de moeda ou divisa para o exterior ou a manutenção de depósitos não declarados à repartição federal competente acabam por lesá-lo". 5 Tal lesão desregula sua função de arrecadar ganhos tributáveis, pois, no presente caso, não há a efetiva tributação ${ }^{6}$; ou seja, o artigo 22 não tutela apenas o

\footnotetext{
${ }^{2}$ SCHMIDT, Andrei Zenkner; FELDENS, Luciano. O crime de evasão de divisas. Rio de Janeiro: Lumen Juris, 2006, p.158.

${ }^{3}$ Id. p. 161.

${ }^{4}$ ALMEIDA DUARTE, Maria Carolina. Crimes contra o sistema financeiro nacional: uma abordagem interdisciplinar. Rio de Janeiro: Lumen Juris, 2003, p.108.

${ }^{5}$ PRADO, Luiz Regis. Direito penal econômico. 2.ed. São Paulo: Revista dos Tribunais, 2007, p. 247.

6 TORTIMA, José Carlos. Crimes contra o sistema financeiro nacional (uma contribuição ao estudo da Lei n $^{\text {7 }}$.492/86). 2.ed. Rio de Janeiro: Lumen Juris, 2002, p.135.
} 
Sistema Financeiro Nacional, comportando, também, a proteção da Ordem Tributária. ${ }^{7}$

Ainda que pese a existência de três condutas penalmente incriminadoras em um mesmo dispositivo legal, cumpre destacar que o sujeito poderá praticar as três figuras típicas ${ }^{8}$ simultaneamente, assim como, as condutas poderão ser praticadas de forma autônoma, não dependendo uma das outras para ocorrer o cometimento do crime ${ }^{9}$. Bem por isso, abordaremos, no presente trabalho, tão somente, as figuras típicas descritas no caput e no parágrafo único, primeira parte, do art. 22 da Lei $n^{\circ} 7.492 / 86$, as quais se interligam diretamente com o sistema compensatório de remessa de valores.

\subsection{DA CONDUTA DE EFETUAR A EVASÃO DE DIVISAS (ART. 22, CAPUT, DA LEI № 7.492/86)}

O caput do artigo 22, da Lei ${ }^{\circ} 74.92 / 1986$, ao criminalizar a conduta de "efetuar operação de câmbio não autorizada, com o fim de promover evasão de divisas do País" inclui no ordenamento jurídico brasileiro, como objeto material, "o valor resultante da operação de câmbio não

\footnotetext{
${ }^{7}$ Nesse sentido Lira afirma: “a criminalização da evasão de divisas visou coibir o desenvolvimento de déficit entre as riquezas que o País produziu, as que deixou de manter em seu território e, ainda, as que não serão tributadas por estarem fora do alcance do fisco, uma vez que toda quantia não declarada deixa de gerar tributos à União". (LIRA, Rafael. O crime de evasão de divisas: análise crítica sobre a atuação da mídia nos processos pré e pós-legislativo. FRANCO, Alberto Silva; LIRA, Rafael (Coord.). Direito penal econômico: questões atuais. p.397-426. São Paulo: Revista dos Tribunais, 2011. p.400).

${ }^{8}$ FELIX, Yuri. Evasão de divisas: breves considerações à luz da política cambial brasileira. FRANCO, Alberto Silva; LIRA, Rafael (Coord.). Direito penal econômico: questões atuais. p.359-378. São Paulo: Revista dos Tribunais, 2011, p.369.

${ }^{9}$ FELIX, Yuri. Evasão de divisas: breves considerações à luz da política cambial brasileira. FRANCO, Alberto Silva; LIRA, Rafael (Coord.). Direito penal econômico: questões atuais. p.359-378. São Paulo: Revista dos Tribunais, 2011, p.369. No entanto, Schmidt e Feldens, entendem haver relação de autonomia relativa entre as definições do artigo 22 da Lei 7.492/86, uma vez que a modalidade prevista no caput do artigo - realização de operação de câmbio não autorizada, com o fim de promover evasão de divisas do País - exige a prévia demonstração de ocorrência de operação de câmbio, enquanto as demais condutas ocorrem independentes umas das outras. (SCHMIDT, Andrei Zenkner; FELDENS, Luciano. O crime de evasão de divisas. Rio de Janeiro: Lumen Juris, 2006, p.159).
} 
autorizada", ${ }^{10}$ razão pela qual sua objetividade jurídica específica reside na proteção sobre "determinadas operações de câmbio destinadas à remessa de valores ao exterior" 11 , primando pelo bom funcionamento do mercado de câmbio e de reservas cambiais. ${ }^{12}$

Desta forma, no intuito de controlar o mercado cambiário, o Banco Central do Brasil impôs limites por meio da criação do RMCCI Regulamento do Mercado de Câmbio e Capitais ${ }^{13}$-, prevendo a necessária formalização das operações de contrato de câmbio, bem como o registro de suas informações no SISBACEN - Sistema de Informações do Banco Central ${ }^{14}$.

Assim, a conduta incriminadora insculpida no caput do artigo 22 é considerada típica, levando em consideração seu caráter comissivo, ou seja, o sujeito ativo para configurar o resultado tipicamente ilícito deve praticar o núcleo do tipo, efetuar operação de câmbio ${ }^{15}$ - compra e venda

${ }^{10}$ SCHMIDT, Andrei Zenkner; FELDENS, Luciano. O crime de evasão de divisas. Rio de Janeiro: Lumen Juris, 2006, p.162. No mesmo sentido: FELIX, Yuri, Evasão de divisas: breves considerações à luz da política cambial brasileira. FRANCO, Alberto Silva; LIRA, Rafael (Coord.). Direito penal econômico: questões atuais. p.359-378. São Paulo: Revista dos Tribunais, 2011, p.370.

${ }^{11}$ SCHMIDT, Andrei Zenkner; FELDENS, Luciano. O crime de evasão de divisas. Rio de Janeiro: Lumen Juris, 2006, p.162. Ainda, para Nucci a "credibilidade do mercado financeiro e a proteção ao investidor" estão diretamente ligadas à objetividade jurídica, na medida em que "a realização de câmbio ilegal, buscando retirar moeda estrangeirado país, tem capacidade de lesar a saúde financeira das instituições, comprometendo a política econômico-financeira do Estado, prejudicando, pois, em último grau, o próprio investidor" (NUCCI, Guilherme de Souza. Leis penais e processuais penais comentadas. 4.ed. São Paulo: Revista dos Tribunais, 2009, p.1114).

${ }^{12}$ SCHMIDT, Andrei Zenkner; FELDENS, Luciano. O crime de evasão de divisas. Rio de Janeiro: Lumen Juris, 2006, p.162; TORTIMA, José Carlos. Crimes contra o sistema financeiro nacional (uma contribuição ao estudo da Lei $\mathrm{n}^{\circ}$ 7.492/86). 2.ed. Rio de Janeiro: Lumen Juris, 2002, p.135. BALTAZAR JUNIOR, José Paulo. Crimes federais. 8.ed. Porto Alegre: Livraria do Advogado, 2012, p.471.

${ }^{13}$ Através da Circular do Banco Central no 3.280/05 e publicações de resoluções do Conselho Monetário Nacional nos 3.265/05 e 3.266/05 foi criado o RMCCI - regulamento do mercado de câmbio e capitais - no qual estão estipuladas todas as determinações concernentes às operações de câmbio cursadas no Mercado de Câmbio do Brasil.

${ }^{14}$ Constitui-se por um "sistema de Informações do Banco Central é um conjunto de recursos de tecnologia da informação, interligados em rede, utilizado pelo Banco Central na condução de seus processos de trabalho". (Banco Central do Brasil. Disponível em http://www.bcb.gov.br/?SISBACEN. Capturado em 25-06-2016).

${ }^{15}$ DELMANTO, Roberto et al. Leis Penais Especiais Comentadas. Rio de Janeiro: Renovar, 2006. p.206. 
de moeda estrangeira ou divisa entre um residente, domiciliado ou com sede do País e outro residente, domiciliado ou com sede no exterior ${ }^{16}$ conjuntamente com o "elemento normativo não autorizado" $"$ " e a pretensão final de agir, que consiste no "fim de promover evasão de divisas"

Significa dizer, portanto, que, para a completa caracterização do crime em comento, é necessário que a operação de câmbio realizada pelo sujeito ativo objetive promover a evasão de divisas, restando insuficiente, tão-somente, a ausência de formalização do contrato de câmbio perante o Banco Central para realização do tipo. ${ }^{19}$

Portanto, a consumação típica da figura do art. 22, caput, da Lei $\mathrm{n}^{\circ} 7.492 / 86$, se dá a partir da transferência de valores - com a finalização do contrato de câmbio - entre um residente no País e outro residente no exterior, ${ }^{20}$ sem a devida formalização da operação perante o Banco Central. Para, além disso, considerando que a figura típica que tratamos somente é admitida na sua forma dolosa, ${ }^{21}$ necessário se faz, para a configuração típica do delito, que o agente pratique o ato descrito como crime, com vontade "consciente da relação de causalidade entre a ação e o resultado" 22 ,

\footnotetext{
${ }^{16}$ BALTAZAR JUNIOR, José Paulo. Crimes federais. 8.ed. Porto Alegre: Livraria do Advogado, 2012, p.472.

${ }^{17}$ DELMANTO, Roberto et al. Leis Penais Especiais Comentadas. Rio de Janeiro: Renovar, 2006. p.206.

${ }^{18}$ DELMANTO, Roberto et al. Leis Penais Especiais Comentadas. Rio de Janeiro: Renovar, 2006. p.206.

19 TORTIMA, José Carlos. Crimes contra o sistema financeiro nacional. 2.ed. Rio de Janeiro: 2002, p.136.

${ }^{20}$ DE SANCTIS, Fausto. Punibilidade no sistema financeiro nacional. Campinas: Millennium, 2003, p.86.

${ }^{21}$ Importa salientar, inclusive, que o tipo penal em comento não pode ter seu cometimento na forma culposa, razão pela qual o agente não poderá ser punido senão por sua forma dolosa, conforme precedente do artigo 18, parágrafo único, do Código Penal: "Salvo os casos expressos em lei, ninguém pode ser punido por fato previsto como crime, senão quando o pratica dolosamente". (FELIX, Yuri. Evasão de divisas: breves considerações à luz da política cambial brasileira. FRANCO, Alberto Silva; LIRA, Rafael (Coord.). Direito penal econômico: questões atuais. p.359-378. São Paulo: Revista dos Tribunais, 2011, p.370.)

${ }^{22}$ GARCIA, Basileu. Instituições de direito penal. São Paulo: Max Limonad, 1982, v. 1, p.277; BITENCOURT, Cezar Roberto. Tratado de direito penal: parte geral. 16.ed. São Paulo: Saraiva, 2011, p.256.
} 
ou seja, que o sujeito ativo tenha sua conduta intencionalmente direcionada à remessa indevida de valores ao exterior. ${ }^{23}$

\subsection{DA CONDUTA DE PROMOVER EVASÃO DE DIVISAS (ART. 22, § ÚNICO, PRIMEIRA PARTE, DA LEI № 7.492/89)}

O legislador, ao incluir o parágrafo único, primeira parte, do artigo 22 da Lei $n^{\circ} 7.492 / 86$, e dispor que incorrerá nas mesmas penas do caput do referido artigo aquele que "a qualquer título, promove, sem autorização le gal, a saída de moeda ou divisa para o exterior" buscou controlar a saída desenfreada de moeda ou divisas para o exterior, pleiteando a regulação, por meio das normas disciplinadoras pelo Banco Central do Brasil,

\footnotetext{
${ }^{23}$ Precedentes jurisprudenciais corroboram que para haver tipicidade na conduta descrita no artigo 22, caput, da Lei 7.492/86 é necessário estar o dolo, como elemento subjetivo, configurado através do fim especial de agir, qual seja: com o fim de promover evasão de divisas do País, senão vejamos: DIREITO PENAL E PROCESSUAL PENAL. HABEAS CORPUS. EVASÃO DE DIVISAS. ELEMENTOS DO TIPO. TRANCAMENTO DA AÇÃO. (...) III - O tipo do art. 22 da Lei 7492-85 exige a que se apresente o elemento subjetivo do tipo "a fim de promover a evasão de divisas", que tem o sentido inequívoco de evadir-se de pagar tributos e de se submeter as regras regulares das operações de câmbio; se o paciente recebe em moeda estrangeira lá residindo não há divisas a evadir (porquanto jamais internalizadas) nem operação de câmbio. IV - A inexistência do elemento subjetivo do tipo descrita como ensejadora do cometimento da conduta torna-a atípica, não se tratando de mero erro de capitulação, de todo perdoável no momento da denúncia e passível de correção por meio da mutatio e da emendatio libelli. V - Ordem deferida, para que se tranque a ação penal, sem prejuízo de nova denúncia, amparada em novos fatos e - ou provas.

(HC 200402010088340, Desembargador Federal ANDRÉ FONTES, TRF2 - SEXTA TURMA, DJU - Data::31/03/2005 - Página:156. Disponível em http://www.jf.jus.br/juris/unificada/Resposta, capturada em 06-10-2012); RECURSO CRIMINAL EM SENTIDO ESTRITO. CRIME CONTRA O SISTEMA FINANCEIRO. LEI 7.492/86, ART. 22, $C A$ $P U T$. EXPORTAÇÃO DE MERCADORIAS SEM CONTRATAÇÃO DE CÂMBIO. REJEIÇÃO DA DENÚNCIA. DECISÃO MANTIDA. (...) 2. O art. 22 da Lei no 7.492/86 é um crime de intenção porque contém o elemento subjetivo do tipo, que se realiza por meio do ato de efetuar a operação de câmbio não autorizada a fim de promover evasão de divisas do país. Trata-se de um crime comissivo, que não prevê forma omissiva. (...) 5. Recurso improvido. (RSE 200204010124405, FÁBIO BITTENCOURT DA ROSA, TRF4 - SÉTIMA TURMA, DJ 11/12/2002 PÁGINA: 1235. Disponível em http://www.jf.jus.br/juris/unificada/Resposta, capturada em 06-10-2012.)
} 
das movimentações financeiras ${ }^{24}$, na busca da "manutenção ou mesmo redirecionamento da política cambial brasileira"25. Desta forma, a objetividade jurídica, em sua amplitude, visa proteger o Sistema Financeiro Nacional. ${ }^{26}$

Na hipótese, pune-se a conduta daquele que providencia materialmente, sem motivação específica (a qualquer título), realiza (ou promove), ${ }^{27}$ a saída de moeda ou divisa, sem autorização legal, para o exterior. $\mathrm{O}$ delito exige que a conduta não esteja devidamente autorizada, para que assim possa ser considerado típico. No entanto, atualmente, o sistema cambiário não exige qualquer espécie de autorização legal para a saída física de moeda ou divisas do País, mas sim uma declaração à autoridade competente quando da saída ou ingresso em território nacional, garantindo, desta forma, a realização das operações cambiárias pela via legal. ${ }^{28} \mathrm{~A}$ regulamentação normativa das operações em espécie é dada pelo artigo 65 da Lei $n^{\circ} 9.069 / 95,{ }^{29}$ ao disciplinar que a remessa de moeda ou de divisas ao exterior que não extrapole ao limite de dez mil reais não será enquadrada na figura típica do artigo 22, parágrafo único, primeira parte. ${ }^{30}$ Do

${ }^{24}$ FELIX, Yuri. Evasão de divisas: breves considerações à luz da política cambial brasileira. FRANCO, Alberto Silva; LIRA, Rafael (Coord.). Direito penal econômico: questões atuais. São Paulo: Revista dos Tribunais, 2011, p.371.

${ }^{25}$ SCHMIDT, Andrei Zenkner; FELDENS, Luciano. O crime de evasão de divisas. Rio de Janeiro: Lumen Juris, 2006, p.174.

${ }^{26}$ SCHMIDT, Andrei Zenkner; FELDENS, Luciano. O crime de evasão de divisas. Rio de Janeiro: Lumen Juris, 2006, p.174.

${ }^{27}$ BALTAZAR JUNIOR, José Paulo. Crimes federais. 8.ed. Porto Alegre: Livraria do Advogado, 2012, p.482.

28 TORTIMA, José Carlos. Crimes contra o sistema financeiro nacional. 2.ed. Rio de Janeiro: 2002, p.140.

${ }^{29}$ Artigo 65. O ingresso no País e a saída do País de moeda nacional e estrangeira devem ser realizados exclusivamente por meio de instituição autorizada a operar no mercado de câmbio, à qual cabe a perfeita identificação do cliente ou do beneficiário. $\S 1^{\circ}$ Excetua-se do disposto no caput deste artigo o porte, em espécie, dos valores: I - quando em moeda nacional, até R\$10.000,00 (dez mil reais); II - quando em moeda estrangeira, o equivalente a R\$ 10.000,00 (dez mil reais); III - quando comprovada a sua entrada no País ou sua saída do País, na forma prevista na regulamentação pertinente. (BRASIL. Lei nº 9.069/95, de 29 de junho de 1995. Dispõe sobre o Plano Real, o Sistema Monetário Nacional, estabelece as regras e condições de emissão do REAL e os critérios para conversão das obrigações para o REAL, e dá outras providências. Diário Oficial da República Federativa do Brasil, 30 jun. 1995. Disponível em http://www.planalto.gov.br/ccivil_03/leis/L9069.htm, capturada em 25-06-2016).

${ }^{30}$ SCHMIDT, Andrei Zenkner; FELDENS, Luciano. O crime de evasão de divisas. Rio de Janeiro: Lumen Juris, 2006, p.176. 
contrário, estando o valor acima do equivalente a dez mil reais, deverá ser efetuada a apresentação da Declaração de Porte de Valores à autoridade alfandegaria, a fim de que o trânsito seja dado dentro dos limites da legalidade. ${ }^{31}$ Desta forma, somente haverá crime, se a remessa extrapolar o limite valorativo de dez mil Reais e a transação estiver desacompanhada da Declaração de Porte de Valores. ${ }^{32}$

Contudo, há posicionamento doutrinário indicando a possibilidade de não haver adequação típica penal na conduta de deixar de declarar os bens e valores, visto que a exigência descrita no tipo é relativa à necessidade de haver autorização, sequer mencionando-se a declaração. ${ }^{33}$

${ }^{31}$ BALTAZAR JUNIOR, José Paulo. Crimes federais. 8.ed. Porto Alegre: Livraria do Advogado, 2012, p.483.

${ }^{32}$ No mesmo sentido discorre a jurisprudência: PENAL. PROCESSUAL PENAL. HABEAS CORPUS. EVASÃO DE DIVISAS. INÉPCIA DA INICIAL. MOVIMENTAÇÕES FINANCEIRAS NÃO FORMALIZADAS. IMPUTADAS FALSIDADES. TIPICIDADE ADMITIDA. HABEAS CORPUS NÃO CONHECIDO. 1. O trancamento da ação penal é medida excepcional, só admitida quando restar provada, de forma clara e precisa, sem a necessidade de exame valorativo do conjunto fático ou probatório, a atipicidade da conduta, a ocorrência de causa extintiva da punibilidade, ou, ainda, a ausência de indícios de autoria ou de prova da materialidade. 2. Não há falar em inépcia, passível do trancamento da ação penal em habeas corpus, se a denúncia indica faticamente os elementos objetivos e subjetivos que compõem o tipo penal imputado, permitindo-se o amplo exercício do direito de defesa. 3. Mesmo antes das circulares do BACEN (ocorridas a partir de 2001), dá-se tipicidade do crime de evasão de divisas quando há transferência internacional de numerário superior a dez mil reais, sem contratação de câmbio formal (registrada no SISBACEN), ou através da Declaração de Porte de Valores (DPV - Resolução/CMN nº 2.254/98), ou, ainda quando fraudulentamente realizada a operação. 4. Habeas Corpus não conhecido. (STJ HC: 87483 SP 2007/0171774-6, Relator: Ministro NEFI CORDEIRO, Data de Julgamento: 22/05/2014, T6 - SEXTA TURMA, Data de Publicação: DJe 16/06/2014)

${ }^{33} \mathrm{Na}$ integralidade da bem lançada advertência de Nunes: "considerando não ser necessária autorização de quem quer que seja para que o cidadão possa fazê-lo, impondo-se-lhe apenas o dever de declaração do porte, cujo descumprimento não pode ser interpretado de forma ampla para fins de adequação típica penal". (NUNES, Ricardo Pieri. Evasão de divisas? Revista Brasileira de Ciências Criminais. São Paulo: Revista dos Tribunais. a. 14. n. 62. p.134-177. set.- out. 2006, p.175). No mesmo sentido Tórtima disciplina: “A rigor, não se pode mais, portanto, pela vigente sistemática das normas cambiais, cogitar-se de hipótese de promovera saída de divisas sem autorização legal, pelo simples motivo de que tal autorização deixou, pelo menos por ora, de vigorar. Melhor teria andado, portanto, o legislador se tivesse empregado no parágrafo único, a expressão por via legal, em vez de sem autorização legal, para designar, assim, qualquer remessa de divisas sem o competente trâmite junto a instituição financeira autorizada e consequentemente comunicação e registro no Banco Central e Receita Federal ou ainda alguma outra operação dessa natureza, realizada 
O delito sob análise consuma-se no exato momento em que o agente efetiva a saída de moeda ou divisa do país. ${ }^{34}$ No entanto, os momentos consumativos se diferenciam de acordo com a modalidade em que a saída se efetivou, "se a evasão é em espécie, tal ocorrerá com a transposição de nossas fronteiras pelo agente que porta a moeda ou as divisas; se a evasão é por meio de câmbio-sacado, verificar-se-á o momento consumativo com a concretização da operação capaz de gerar a disponibilidade no exterior". ${ }^{35}$ Desta forma, o tipo penal somente se consumará a partir do momento em que os valores ou divisas estiverem disponíveis no exterior, seja pela transposição de fronteiras (espécie), seja por contratos de câmbios (sacado). ${ }^{36}$

Sendo assim, pode-se dizer que a conduta disposta no caput, do artigo 22, da Lei ${ }^{\circ} 7.492 / 86$, somente poderá ser considerada consumada a partir da transferência de valores - com a finalização do contrato de câmbio - entre um residente no País e outro residente no exterior, ${ }^{37}$ enquanto que a figura típica do parágrafo único, primeira parte, depende, para sua consumação, tão-somente, da efetiva saída de moeda ou divisa do Brasil. ${ }^{38}$ De acordo com o delito em questão, será possível identificar, então, a possibilidade ou não das operações dólar-cabo serem consideradas típicas, na

mediante fraude." (TÓRTIMA, José Carlos. Crimes contra o sistema financeiro nacional. Rio de Janeiro: Lumen Juris, 2000, p.144).

${ }^{34}$ BALTAZAR JUNIOR, José Paulo. Crimes federais. 8.ed. Porto Alegre: Livraria do Advogado, 2012, p.485.

${ }^{35}$ SCHMIDT, Andrei Zenkner; FELDENS, Luciano. O crime de evasão de divisas. Rio de Janeiro: Lumen Juris, 2006, p.175.

${ }^{36}$ A jurisprudência discorre sobre uma das formas de consumação, qual seja contratos de câmbio-sacado: PENAL. PROCESSO PENAL. EVASÃO DE DIVISAS. ARTIGO 22, $C A$ $P U T$, DA LEI N ${ }^{\circ}$ 7.492/86. REMESSA DE DIVISAS AO EXTERIOR. AUSÊNCIA DE VINCULAÇÃO DAS DECLARAÇÕES DE IMPORTAÇÃO AOS CONTRATOS DE CÂMBIO. AUSÊNCIA DE PROVA DE INTERNALIZAÇÃO DA MERCADORIA OU REPATRIAÇÃO DO NUMERÁRIO. Configura o delito de evasão de divisas, previsto no art. 22, caput, da Lei $\mathrm{n}^{\circ}$ 7.492/86, a remessa de moeda para o exterior, mediante a realização de contratos de câmbio sem o devido fechamento, e sem a demonstração da internalização da correspondente mercadoria ou da repatriação do numerário. (TRF4, ACR 2004.70.00.025623-3, Sétima Turma, Relator Luiz Carlos Canalli, D.E. 31/05/2012). Disponível em http://jurisprudencia.trf4.jus.br/pesquisa.

${ }^{37}$ DE SANCTIS, Fausto. Punibilidade no sistema financeiro nacional. Campinas: Millennium, 2003, p.86.

${ }^{38}$ BATISTA, Nilo. Consumação e tentativa do crime de evasão de divisas. SCHECARIA, Sérgio Salomão (Org.). Estudos criminais em homenagem a Evandro Lins e Silva (criminalista do século). p.249- 255. São Paulo: Método, 2001, p.255. 
forma do artigo 22, caput ou parágrafo único, primeira parte, da Lei $\mathrm{n}^{\circ}$ 7.492/86.

\section{DAS OPERAÇÕES DÓLAR-CABO}

As denominadas operações dólar-cabo ganharam destaque após o desmantelamento, pela Polícia Federal, de diversas investigações envolvendo pessoas públicas e renomadas empresas ${ }^{39}$ na prática de remessa de valores ao exterior por um modus operandi ${ }^{40}$ diverso, sem registro oficial.

Assim, as chamadas operações dólar-cabo são "um sistema internacional de compensação paralelo, sem registro nos órgãos oficiais, pelo qual o interessado em remeter dinheiro para o exterior repassa recursos sem origem conhecida ou declarada para um doleiro no Brasil". ${ }^{41}$

O funcionamento do sistema de compensação, denominado dólar-cabo, como via alternativa de remessa de valores, pode acontecer por meio de três modalidades distintas: na primeira, o doleiro ${ }^{42}$ recebe do cliente os valores em Reais, no Brasil, e disponibiliza, em moeda estrangeira,

${ }^{39}$ LIRA, Paulo Fernandes. A atipicidade da operação dólar-cabo ou hawala em face do crime de evasão de divisas. FRANCO, Alberto Silva; LIRA, Rafael (Coord.). Direito penal econômico: questões atuais. p.379-396. São Paulo: Revista dos Tribunais, 2011, p.381. Dentre as operações realizadas pela Polícia Federal, destaca-se a famosa operação Farol da Colina que investigou o banqueiro Daniel Dantas, a apresentadora Xuxa Meneghel, o jogador de futebol Romário, a empresa Beacon Hill, dentre outras. (BALTAZAR JUNIOR, José Paulo. Crimes federais. 8.ed. Porto Alegre: Livraria do Advogado, 2012, p.474).

${ }^{40}$ SCHMIDT, Andrei Zenkner; FELDENS, Luciano. O crime de evasão de divisas. Rio de Janeiro: Lumen Juris, 2006, p.221.

${ }^{41}$ Conceituação dada pelo Ministro do Supremo Tribunal Federal, Dias Toffoli, quando do julgamento do Ação Penal no 470, relativo a imputações de evasão de divisas, no caso do publicitário Duda Mendonça e de sua sócia Zilmar Fernandes. Disponível em http://www.stf.jus.br/portal/cms/verNoticiaDetalhe.asp?idConteudo=221138, capturada em 25-06-2016.

42 Doleiro: “Alcunha ainda sem definição jurídica, subentendido como o agente responsável pela intermediação das operações nacionais e estrangeiras, em troca de comissões ou vantagens adquiridas com a majoração das taxas cambiais aplicadas." (LIRA, Paulo Fernandes. A atipicidade da operação dólar-cabo ou hawala em face do crime de evasão de divisas. FRANCO, Alberto Silva; LIRA, Rafael (Coord.). Direito penal econômico: questões atuais. p.379-386. São Paulo: Revista dos Tribunais, 2011, p.381). 
o equivalente no exterior; ${ }^{43}$ na segunda, o caminho é inverso, o cliente disponibiliza ao doleiro recursos em moeda estrangeira, no exterior, e o doleiro entrega no Brasil o crédito em reais; ${ }^{44}$ na terceira, o doleiro utiliza-se de um banco de compensações, uma vez que aproveita clientes que estão nas duas posições, um querendo remeter valores do exterior ao Brasil e outro do Brasil para o exterior, desta forma os recursos são trocados, e a titularidade do doleiro sequer aparece nas transações. Estas condutas "são realizadas na base da pura confiança, pois nenhum comprovante é fornecido ao interessado que, deste modo, nada poderá reclamar em caso de falhas ou má-fé por parte dos 'banqueiros"”. ${ }^{45}$

Feldens e Schmidt, ainda, observam que o esquema de compensação, manejado por doleiros, vai além das fronteiras territoriais, tendo em vista que a evolução dos meios de comunicação e de acesso às redes bancárias possibilita cada vez mais o relacionamento entre doleiros de todas as partes do mundo. ${ }^{46}$ Assim, para confirmar a remessa de valores ao exterior, basta o envio de uma mensagem, por fax, e-mail ou telefonia, por meio de um comunicador instantâneo, entre o agente e o doleiro. ${ }^{47}$

Desta forma, quer nos parecer que não há registro de transferência bancária capaz de unir a fonte originária dos valores remetidos do país

\footnotetext{
${ }^{43}$ In litteris: "o doleiro recebe do interessado dinheiro no Brasil em moeda corrente, em nome próprio ou de "laranjas", para em contrapartida providenciar, com recursos alocados em contas que mantém no exterior em nome próprio ou de terceiros, desconhecidas das autoridades pátrias, o depósito da quantia correspondente convertida para a moeda do país estrangeiro eleito pelo beneficiário da transação, que então alimente conta que ali já mantinha ou passa a manter". NUNES, Ricardo Pieri. Evasão de divisas? Revista Brasileira de Ciências Criminais. São Paulo: Revista dos Tribunais. a. 14. n. 62. p.134-177. set.- out. 2006, p.586-587.

${ }^{44}$ SCHMIDT, Andrei Zenkner; FELDENS, Luciano. O crime de evasão de divisas. Rio de Janeiro: Lumen Juris, 2006, p.222.

${ }^{45}$ RATTI, Bruno. Comércio internacional e câmbio. 10.ed. São Paulo: Aduaneiras, 2004, p.133.

${ }^{46}$ Denúncia oferecida pelo Ministério Público Federal com base nos procedimentos da Justiça Federal em Curitiba números 2003.70.00.036510-8 (IPL 633/03), 2003.70.00.0365121 (IPL 924/03), 2003.70.00.033588-8 (IPL 492/03), subscrita pelos procuradores Carlos Fernando dos Santos Lima, Januário Paludo, Deltan Matinazzo Dallagnol, Orlando Martello Junior e Vladimir Aras. (Citado por SCHMIDT, Andrei Zenkner; FELDENS, Luciano. O crime de evasão de divisas. Rio de Janeiro: Lumen Juris, 2006, p.222.).

47 ARAS, Vladimir. Lavagem de dinheiro, evasão de divisas e cooperação internacional. Rocha, João Carlos de Carvalho et al. (Coord.). Crimes contra o sistema financeiro nacional: 20 anos da Lei 7.492/1986. p.197-240. Belo Horizonte: Del Rey, 2006, p.213.
} 
de origem e a receptora no país de destino, e sequer documentos hábeis a comprovar a existência de vínculo entre o operador (doleiro) e o cliente. ${ }^{48}$

\section{DA ANÁLISE DA TIPICIDADE DAS OPERAÇÕES DÓLAR-CABO EM FACE DO CRIME DE EVASÃO DE DIVISAS}

As denominadas operações dólar-cabo, como visto acima, basicamente ocorrem quando o doleiro disponibiliza recursos, que já se encontram no exterior, em favor de terceiro, mediante depósito em reais na conta mantida no Brasil. "Assim, o doleiro passa a titular os reais no Brasil e o seu cliente recebe, na conta que indicou no exterior, o crédito no valor correspondente na moeda solicitada". ${ }^{49}$

Pois bem, em termos de tipicidade, a conduta de compensação de valores não pode ser enquadrada nas iras do artigo 22 , caput e parágrafo único, primeira parte, da Lei $\mathrm{n}^{\circ} 7.492 / 86$, uma vez que nenhuma divisa sai, efetivamente, do País, ${ }^{50}$ o que não fere ou coloca em risco a regular execução da política cambial brasileira, que é o bem jurídico tutelado pela norma. Como visto, se entende este crime como sendo formal, dispensando a ocorrência de resultado naturalístico para sua consumação, e, em virtude disso, crime de perigo. Estes são os que demandam uma análise inicial sobre o objeto de tutela jurídica e, ao depois, a consideração se a realização da conduta típica (não o acontecimento em concreto) representa dano, perigo, ou se deixa o bem jurídico inalterado. ${ }^{51}$

Bem por isso, sobre o tipo penal do caput do artigo 22 da Lei ${ }^{\circ}$ 7.492/1986, tendo em vista seu momento consumativo, que se dá mediante

\footnotetext{
${ }^{48}$ No mesmo sentido: ARAS, Vladimir. Lavagem de dinheiro, evasão de divisas e cooperação internacional. Rocha, João Carlos de Carvalho et al. (Coord.). Crimes contra o sistema financeiro nacional: 20 anos da Lei 7.492/1986. p.197-240. Belo Horizonte: Del Rey, 2006, p.213.

${ }^{49}$ SCHMIDT, Andrei Zenkner; FELDENS, Luciano. O crime de evasão de divisas. Rio de Janeiro: Lumen Juris, 2006, p.223.

${ }^{50}$ NUNES, Ricardo Pieri. Evasão de divisas? Revista Brasileira de Ciências Criminais. São Paulo: Revista dos Tribunais. a. 14. n. 62. p.134-177. set.- out. 2006, p.160

${ }^{51}$ FRAGOSO, Heleno Cláudio. Lições de direito penal: parte geral. 16.ed. Rio de Janeiro: Forense, 2003, p.207.
} 
o fechamento de contrato de câmbio ${ }^{52}$, diz-se que sua objetividade jurídica, portanto, recairá sobre as operações cambiais ${ }^{53}$, da mesma forma, a primeira parte do parágrafo único do artigo 22 tem o delito como consumado somente com a disponibilização dos valores no exterior, os quais foram remetidos sem a devida autorização legal, resultando, de igual forma, a tutela penal na regulação das movimentações financeiras, ${ }^{54}$ na busca da manutenção da política cambial brasileira. Ou seja, considerando que o delito de evasão de divisas, nas suas duas modalidades típicas, caracteriza-se pela proteção a política cambial, constata-se que somente será desestruturado o bem jurídico, se ocorrerem remessas de valores ao exterior sem o regular controle estatal.

Por certo, o sistema de compensação de valores (dólar-cabo) ocorrendo com recursos já mantidos no exterior, não exige a evasão de divisas ou a existência de operação de câmbio irregular ${ }^{55}$ no momento da disponibilização do crédito, razão pela qual a operação dólar-cabo não pode ser considerada como ameaça à tutela penal do artigo 22 da Lei $\mathrm{n}^{\mathbf{o}}$ 7.492/86, pois a estabilidade do fluxo cambial, como parte integrante da política cambial, permanece íntegra, devido ao fato de que não há remessa de valores ao exterior, mas sim uma simples compensação. ${ }^{56}$

${ }^{52}$ DE SANCTIS, Fausto. Punibilidade no sistema financeiro nacional. Campinas: Millennium, 2003, p.86.

${ }^{53}$ SCHMIDT, Andrei Zenkner; FELDENS, Luciano. O crime de evasão de divisas. Rio de Janeiro: Lumen Juris, 2006, p.162.

${ }^{54}$ FELIX, Yuri. Evasão de divisas: breves considerações à luz da política cambial brasileira. FRANCO, Alberto Silva e LIRA, Rafael (Coord.). Direito penal econômico: questões atuais. p.359-378. São Paulo: Revista dos Tribunais, 2011, p.371.

55 "Para que aquele dispositivo incida, é necessário que o indivíduo tenha promovido a evasão de divisas do país, ou quando menos, efetuado operação de câmbio irregular, com tal propósito" (CRUZ, Flávio Antônio da. Gestão temerária, evasão de divisas e aporias. PRADO, Luiz Regis; DOTTI, René Ariel (orgs.) Direito penal econômico e da empresa: Direito penal econômico. v.2. p.679-724. São Paulo: Revista dos Tribunais, 2011, p.719).

${ }^{56}$ Nesse sentido Lira discorre: "as denominadas operações hawala, ocorrem com recursos já mantidos no exterior, em contas de titularidade ou não de cidadãos brasileiros, e transferidos em favor de terceiros que efetuam o pagamento correspondente em depósito bancário ou moeda nacional ou estrangeira em solo brasileiro. Nesses casos, temeroso que se fale em evasão de divisas ou manutenção de depósitos no exterior, não declarados à repartição pública competente, se que se analise o elemento subjetivo que direcionou a conduta do agente e o bem jurídico lesado, pois sem dúvida, os recursos já estão fora do país, incumbindo ao Estado verificar de que forma e quando lá chegaram, e de onde partiram, sendo que tal conduta não se subsumiria ao tipo penal previsto no art. 22 da Lei 7.492/86". (LIRA, Paulo Fernandes. A atipicidade da operação dólar-cabo ou hawala em face do crime de evasão de 
Importante dizer, no entanto, que, além de não haver lesão ao bem jurídico tutelado pelo delito de evasão de divisas, as operações dólarcabo, no que se refere à primeira parte do parágrafo único, do artigo 22, da Lei $n^{\circ} 7.492 / 1986$, também são consideradas atípicas, uma vez que as divisas, objeto da operação, já estão armazenadas no exterior. ${ }^{57}$

Para bem da verdade, "a ausência de divisas já evadidas (já ocultadas ao Estado) não pode significar evasão, assim como quem lança fogo em algo já incendiado não responde por dano". ${ }^{58}$

A hipótese de cabimento de eventual ocorrência do delito de evasão de divisas pode se dar em momento anterior à ocorrência da operação dólar-cabo, tratando-se então de uma questão temporal, ou seja, "no momento em que ocorre a denominada operação dólar-cabo, necessariamente já teria de haver ocorrido a evasão de divisas ou moeda, com o fechamento da operação não autorizada se exaurindo com a irregular remessa para o exterior". ${ }^{59}$ Da mesma forma, a remessa de moeda ou divisa ao exterior, que possibilitará a ação do doleiro, poderá se dar de forma legal, obedecendo todos os limites impostos pelo legislador.

Veja-se que o reconhecimento da atipicidade das operações dólar-cabo, por se tratar de um esquema compensatório em que o dinheiro objeto da operação já se encontra no exterior e lá permanece, não pode se levar a subsumir ao delito de evasão de divisas, isso porque, além de não afrontar o bem jurídico tutelado pela norma, não há redução das reservas

divisas. FRANCO, Alberto Silva; LIRA, Rafael (Coord.). Direito penal econômico: questões atuais. p.379-396. São Paulo: Revista dos Tribunais, 2011. p.387).

${ }^{57}$ CRUZ, Flávio Antônio da. Gestão temerária, evasão de divisas e aporias. PRADO, Luiz Regis; DOTTI, René Ariel (orgs.). Direito penal econômico e da empresa: Direito penal econômico. v.2. p.679-724. São Paulo: Revista dos Tribunais, 2011, p.720. No mesmo sentido: TÓRTIMA, José Carlos. Evasão de divisas. Rio de Janeiro: Lumen Juris, 2006. Para Delmanto "na operação dólar-cabo não há qualquer evasão de divisas. O dinheiro objeto da operação já estava no exterior e lá continua. Há, na verdade, uma compensação, que não se confunde com operação de câmbio não autorizada com o fim de promover evasão de divisas do País. Com esse tipo de operação não sai, do Brasil, um único Real”. (DELMANTO, Roberto et al. Leis Penais Especiais Comentadas. Rio de Janeiro: Renovar, 2006. p.208.).

${ }^{58}$ CRUZ, Flávio Antônio da. Gestão temerária, evasão de divisas e aporias. PRADO, Luiz Regis; DOTTI, René Ariel (orgs.). Direito penal econômico e da empresa: Direito penal econômico. v.2. p.679-724. São Paulo: Revista dos Tribunais, 2011, p.719.

${ }^{59}$ LIRA, Paulo Fernandes. A atipicidade da operação dólar-cabo ou hawala em face do crime de evasão de divisas. FRANCO, Alberto Silva; LIRA, Rafael (Coord.). Direito penal econômico: questões atuais. p.379-396. São Paulo: Revista dos Tribunais, 2011. p.391. 
brasileiras, ${ }^{60}$ ou seja, o Sistema Financeiro Nacional e a política cambial permanecem hígidos, sem qualquer lesão.

Assim, é possível verificar, ainda, uma terceira hipótese em que a atipicidade da operação dólar-cabo face ao delito de evasão de divisas se evidencia. ${ }^{61}$ Sabendo-se que o caput do artigo 22 da Lei $\mathrm{n}^{\circ} 7.492 / 86$ e a conduta disposta na primeira parte do parágrafo único do mesmo dispositivo têm como característica própria e necessária à consumação dos tipos a realização de operação de câmbio entre um residente no país e outro residente no exterior, ${ }^{62}$ é de observar-se que não há o cometimento desta modalidade de injusto quando se tratar das operações dólar-cabo. ${ }^{63}$ Parecenos evidente que a compensação de valores pela via dólar-cabo, consistente na disponibilização de recursos no exterior de um doleiro residente no Brasil a um cliente, também residente no Brasil, em moeda estrangeira pertencente ao estoque de divisas de outro país, não provoca baixa nas divisas brasileiras, tendo em vista que a disponibilização se deu por compensação clandestina, deixando de ser contabilizada no controle do Banco Central do Brasil. ${ }^{64}$

${ }^{60}$ NUNES, Ricardo Pieri. Evasão de divisas? Revista Brasileira de Ciências Criminais. São Paulo: Revista dos Tribunais. a. 14. n. 62. p.134-177. set.- out. 2006, p.174. No mesmo sentido: LIRA, Paulo Fernandes. A atipicidade da operação dólar-cabo ou hawala em face do crime de evasão de divisas. FRANCO, Alberto Silva; LIRA, Rafael (Coord.). Direito penal econômico: questões atuais. p.379-396. São Paulo: Revista dos Tribunais, 2011. p.392; DELMANTO, Roberto et al. Leis Penais Especiais Comentadas. Rio de Janeiro: Renovar, 2006. p.208. Em sentido contrário, Baltazar Junior colaciona que "toda operação de câmbio efetuado fora do mercado oficial, ou seja, sem a intermediação de um estabelecimento autorizado a operar no mercado cambial, no chamado câmbio paralelo, é considerada irregular e, portanto, não autorizada".(BALTAZAR JUNIOR, José Paulo. Crimes federais. 8.ed. Porto Alegre: Livraria do Advogado Editora, 2012, p.474). Para Schmidt e Feldens a disponibilidade de divisas ou valores no exterior utilizando-se do sistema de compensação, "evidentemente, efetivado à margem de qualquer controle pelo BACEN, o que caracteriza a realização de operação sem autorização legal (...)". (SCHMIDT, Andrei Zenkner; FELDENS, Luciano. O crime de evasão de divisas. Rio de Janeiro: Lumen Juris, 2006, p.224). ${ }^{61}$ NUNES, Ricardo Pieri. Evasão de divisas? Revista Brasileira de Ciências Criminais. São Paulo: Revista dos Tribunais. a. 14. n. 62. p.134-177. set.- out. 2006, p.159.

${ }^{62}$ BALTAZAR JUNIOR, José Paulo. Crimes federais. 8.ed. Porto Alegre: Livraria do Advogado, 2012, p.472

${ }^{63}$ NUNES, Ricardo Pieri. Evasão de divisas? Revista Brasileira de Ciências Criminais. São Paulo: Revista dos Tribunais. a. 14. n. 62. p.134-177. set.- out. 2006, p.159.

${ }^{64}$ Para Nunes "não havendo transferência de titularidade de moeda entre um residente e um não residente, não há que se cogitar de evasão, fuga ou saída de divisas do país, de sorte que as transações cambiais clandestinas entre residentes no Brasil, visando a disponibilização de recursos no exterior, malgrado eventualmente ilícitas, não possuem o condão de 
Cumpre, igualmente, destacar que quem utilizar-se da operação dólar-cabo estará, tão somente, incorrendo em infração administrativa, dado que o artigo 10 do Decreto Lei ${ }^{\circ}$ 9.025/1946 $6^{65}$ combinado com o artigo $1^{\circ}$ do Decreto $n^{\circ} 23.258 / 1933{ }^{66}$ estabelecem vedação à compensação privada de créditos, o que não implica - tão só por isso - ser conduta penalmente típica. ${ }^{67}$

Quer nos parecer, então, que tanto a hipótese do caput (operação de câmbio com o fim de promover a evasão de divisas), quanto a primeira parte, do parágrafo único, do artigo 22, da Lei $n^{\circ}$ 7.492/86, (efetiva remessa de valores) não podem ser utilizadas para reprimir as operações dólar-cabo, uma vez que, em não havendo remessa de valores ao exterior; ou seja, não havendo câmbio irregular, tendo em vista que os valores já se encontram no exterior, não há afronta à política cambial brasileira, e sequer tipicidade objetiva dos dispositivos, primeiro, pois ausente o elemento subjetivo do tipo (evasão de divisas), segundo, porque as divisas/valores além de já se encontrarem no exterior serão disponibilizadas por um residente no Brasil a outro residente, o que mantém as reservas cambiais hígidas, sem qualquer intervenção.

provocar baixas nas reservas do Banco Central" (NUNES, Ricardo Pieri. Evasão de divisas? Revista Brasileira de Ciências Criminais. São Paulo: Revista dos Tribunais. a. 14. n. 62. p.134-177. set.- out. 2006, p.162).

${ }^{65}$ Artigo. 10. É vedada a realização de compensação privada de créditos ou valores de qualquer natureza, sujeitos os responsáveis às penalidades previstas no Decreto ${ }^{\circ} 23.258$, de 19 de Janeiro de 1933. (BRASIL. Decreto Lei n ${ }^{\circ} 9.025$, de 27 de fevereiro de 1946. Dispõe sobre as operações de câmbio, regulamenta o retorno de capitais estrangeiros e dá outras providências. Diário Oficial da República Federativa do Brasil, 28 fev. 1946. Disponível em https://www.planalto.gov.br/ccivil_03/decreto-lei/1937-1946/Del9025.htm, capturado em 01-11-2012.).

${ }^{66}$ Artigo. $1^{\circ}$. São consideradas operações de câmbio ilegítimas as realizadas entre bancos, pessoas naturais ou jurídicas, domiciliadas ou estabelecidas no país, com quaisquer entidades do exterior, quando tais operações não transitem pelos bancos habilitados a operar em câmbio, mediante prévia autorização da fiscalização bancária a cargo do Banco do Brasil. (BRASIL. Decreto $\mathrm{n}^{\circ}$ 23.248, de 19 de outubro de 1933. Dispõe sobre as operações de câmbio, e dá outras providências. Diário Oficial da União, 19 out. 1933. Disponível em http://www.bcb.gov.br/pre/leisedecretos/Port/dec23258.pdf, capturado em 01-11-2012.

${ }^{67}$ CRUZ, Flávio Antônio da. Gestão temerária, evasão de divisas e aporias. PRADO, Luiz Regis; DOTTI, René Ariel (orgs.). Direito penal econômico e da empresa: Direito penal econômico. v.2. p.679-724. São Paulo: Revista dos Tribunais, 2011, p.720. No mesmo sentido: LIRA, Paulo Fernandes. A atipicidade da operação dólar-cabo ou hawala em face do crime de evasão de divisas. FRANCO, Alberto Silva; LIRA, Rafael (Coord.). Direito penal econômico: questões atuais. p.379-396. São Paulo: Revista dos Tribunais, 2011. p.387. 
Por certo, então, mostra-se claro que a operação dólar-cabo, em que pese ilícita, não pode ser enquadrada no tipo penal do artigo 22 da Lei $\mathrm{n}^{\mathrm{o}} 7.492 / 1986$, uma vez que não se faz presente o elemento típico objetivo capaz de incriminar a conduta.

\section{CONSIDERAÇÕES FINAIS}

O presente trabalho buscou trazer as principais conclusões sobre a tutela penal no controle do tráfego de moeda, especificadamente no que se refere à atipicidade penal das operações dólar-cabo. Com esse objetivo, analisaram-se as duas das hipóteses legais constantes no artigo 22 da Lei $\mathrm{n}^{\mathrm{o}} 7.492 / 1986$, para, finalmente, discorrer acerca do sistema paralelo de remessa de valores ao exterior, denominado dólar-cabo, e analisar seu enquadramento típico.

Assim, ainda que se possa considerar duvidoso o caráter das operações dólar-cabo, não se pode garantir, por certo, e tão somente por isso, que ela se enquadre nas iras do artigo 22, caput, ou $\S$ único, primeira parte, da Lei $n^{\circ} 7.492 / 1986$, dado que além de não haver afronta direta à política cambial brasileira, tutela penal do tipo, não se encontram presentes os requisitos necessários de tipicidade objetiva do referido delito.

\section{BIBLIOGRAFIA}

ALMEIDA DUARTE, Maria Carolina. Crimes contra o sistema financeiro nacional: uma abordagem interdisciplinar. Rio de Janeiro: Lumen Juris, 2003.

ARAS, Vladimir. Lavagem de dinheiro, evasão de divisas e cooperação internacional. Rocha, João Carlos de Carvalho et al. (Coord.). Crimes contra o sistema financeiro nacional: 20 anos da Lei 7.492/1986. p. 197-240. Belo Horizonte: Del Rey, 2006.

BALTAZAR JUNIOR, José Paulo. Crimes federais. 8.ed. Porto Alegre: Livraria do Advogado, 2012.

BATISTA, Nilo. Consumação e tentativa do crime de evasão de divisas. SCHECARIA, Sérgio Salomão (Org.). Estudos criminais em homenagem a Evandro Lins e Silva (criminalista do século). p. 249- 255. São Paulo: Método, 2001.

BITENCOURT, Cezar Roberto. Tratado de direito penal: parte geral. 16.ed. São Paulo: Saraiva, 2011. 
CRUZ, Flávio Antônio da. Gestão temerária, evasão de divisas e aporias. PRADO, Luiz Regis; DOTTI, René Ariel (orgs.) Direito penal econômico e da empresa: Direito penal econômico. v.2. p. 679-724. São Paulo: Revista dos Tribunais, 2011.

DE SANCTIS, Fausto. Punibilidade no sistema financeiro nacional. Campinas: Millennium, 2003.

DELMANTO, Roberto et al. Leis Penais Especiais Comentadas. Rio de Janeiro: Renovar, 2006.

FELIX, Yuri. Evasão de divisas: breves considerações à luz da política cambial brasileira. FRANCO, Alberto Silva; LIRA, Rafael (Coord.). Direito penal econômico: questões atuais. p. 359-378. São Paulo: Revista dos Tribunais, 2011.

FRAGOSO, Heleno Cláudio. Lições de direito penal: parte geral. 16.ed. Rio de Janeiro: Forense, 2003.

GARCIA, Basileu. Instituições de direito penal. v. 1. São Paulo: Max Limonad, 1982.

LIRA, Paulo Fernandes. A atipicidade da operação dólar-cabo ou hawala em face do crime de evasão de divisas. FRANCO, Alberto Silva; LIRA, Rafael (Coord.). Direito penal econômico: questões atuais. p. 379-396. São Paulo: Revista dos Tribunais, 2011.

LIRA, Rafael. O crime de evasão de divisas: análise crítica sobre a atuação da mídia nos processos pré e pós-legislativo. FRANCO, Alberto Silva; LIRA, Rafael (Coord.). Direito penal econômico: questões atuais. p. 397-426. São Paulo: Revista dos Tribunais, 2011.

NUCCI, Guilherme de Souza. Leis penais e processuais penais comentadas. 4.ed. São Paulo: Revista dos Tribunais, 2009.

NUNES, Ricardo Pieri. Evasão de divisas? Revista Brasileira de Ciências Criminais. São Paulo: Revista dos Tribunais. a. 14. n. 62. p. 134-177. set.- out. 2006.

PRADO, Luiz Regis. Direito penal econômico. 2.ed. São Paulo: Revista dos Tribunais, 2007.

RATTI, Bruno. Comércio internacional e câmbio. 10.ed. São Paulo: Aduaneiras, 2004.

SCHMIDT, Andrei Zenkner; FELDENS, Luciano. O crime de evasão de divisas. Rio de Janeiro: Lumen Juris, 2006.

TORTIMA, José Carlos. Crimes contra o sistema financeiro nacional (uma contribuição ao estudo da Lei nº 7.492/86). 2.ed. Rio de Janeiro: Lumen Juris, 2002. 